\title{
A Review of Shaped Charge Variables for its Optimum Performance
}

\author{
Khalid Naeem \\ School of Chemical and Materials \\ Engineering, National University of \\ Sciences and Technology \\ Islamabad, Pakistan \\ khalid.phd@scme.nust.edu.pk
}

\author{
Arshad Hussain \\ School of Chemical and Materials \\ Engineering, National University of \\ Sciences and Technology \\ Islamabad, Pakistan \\ principal@scme.nust.edu.pk
}

\author{
Shakeel Abbas \\ Al-Technique Corporation of Pakistan \\ Islamabad, Pakistan \\ shakeelabbas@hotmail.com
}

\begin{abstract}
Shaped charge is a device for focusing the chemical energy of explosives to a particular point or line for penetration or cutting purpose respectively. They are used for the penetration or cutting of various types of targets on land, water, underground, underwater, or air. Their shape is either conical or linear and consists of explosive, casing and liner. The liner is bent towards the central axis producing a thin hypervelocity jet by the energy released as a result of the explosive detonation. This jet is utilized against the target. Shaped charges can perforate or penetrate targets like aircrafts, ships, submarines, armored vehicles, battle tanks, and bunkers. This paper presents a detailed review of analytical works, computer simulations, and experimental results related to the liner. Among modern diagnostic techniques flash $x$-rays, radiography is the best and widely used in the experiments performed in the last 40 years. Powder metallurgy, which started in the late twentieth century raised the efficiency of shaped charges to new altitudes. The efficiency of the shaped charge depends on numerous factors such as explosive's type, liner's material, geometry and metallurgy, manufacturing technique, and casing thickness. Factors concerning the liner's material, metallurgical advancements, and geometry are discussed chronologically and in detail.
\end{abstract}

Keywords-conical liners; hemispherical liners; sintered powder liners; rolled homogenous armor

\section{INTRODUCTION}

A shaped charge is an explosive cylinder with a cavity opposite to the detonation point. The shape of the cavity may vary from conical to bow-shape. The cavity in the explosive is either empty or may contain a liner made of metal, alloy or any other material, a status known as hollow charge and shaped charge respectively. A typical shaped charge is shown in Figure 1. The shaped charge is known by different names in different parts of the globe, for example, hohlladung [1] and cumulative charge [2] in Germany and the Soviet Union respectively. Liners for shaped charges are manufactured according to the requirements in the form of cone, parabola, hemisphere, Vshape or any other suitable form [3]. The $\mathrm{V}$-shaped liner is also known as linear cutting charge used mainly for demolition purposes [4]. Detonating a hollow cylindrical charge on or near the target produces a deeper cavity in the target than a cylindrical explosive without a cavity. This is known as the Corresponding author: Khalid Naeem
Neumann or Munroe effect [5]. In case of the lined cavity and axial symmetric geometries, an outgoing spherical detonation wave is produced from the detonation point. The detonation wave moves toward the liner at a speed of 5000 to $8000 \mathrm{~m} / \mathrm{s}$ dictated by the type of explosive [6]. The detonation wave exerts a pressure in the range of twenty to two thousand GPa on the liner which behaves as an inviscid incompressible fluid [7]. This pressure causes the liner to collapse at a strain rate of $10^{4} \mathrm{~s}^{-1}$ to $10^{7} \mathrm{~s}^{-1}$. The collapse of the liner starts from the apex toward the centerline to form a jet. As the detonation wave progresses on the liner towards the base a big chunk of the liner flows into a slug. Typical velocities of the jet and slug are 10,000 and $1,000 \mathrm{~m} / \mathrm{s}$ respectively [3]. This velocity gradient produces elongation in the jet, causing necking or breakup of the jet [8]. The high-velocity jet exerts pressure on the target which exceeds the target strength resulting in penetration [9]. At these high velocities the penetration of the jet is independent of the target strength but instead depends on its density [10]. The cavity is produced by the lateral displacement of the material due to intense pressure. The cavity further deepens when the shaped charge is moved a certain optimal distance away from the target known as standoff (SO). The SO depends on the size, geometry and the type of the explosive used in the shaped charge [11]. Shaped charges are utilized for hypervelocity impact in space-related studies [12].

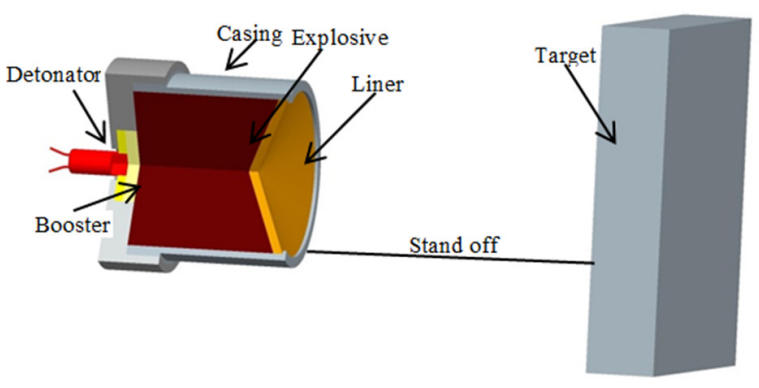

Fig. 1. Cutview of a shaped charge with a target

II. HISTORY OF SHAPED CHARGES

The history of shaped charges begins with the utilization of the unlined cavity charge by Franz in 1792 using black powder 
which deflagrates. At that time there was no concept of detonation or detonator. After the invention of the detonator, Foerster in 1833 successfully detonated the unlined cavity charge [13]. The invention of detonating caps patented by Bloem can be regarded as the first lined cavity [14]. Later on, Munroe also performed experiments in the United States on the unlined and lined cavity [15]. To optimize the performance of shaped charges, multiple variables like casing material, casing thickness, high explosive type, liner to explosive mass ratio, cone angle, manufacturing technique of the liner, insertion of wave-shaper, grain size control, liner material, thickness, geometry, SO distance, cone angle, bimetallic liner and multimaterial liners have been studied one by one or in parallel. Optimization by wave-shaper and its effect on the detonation wave-front was conducted in [16]. A detailed work on the shaped charges can be seen in [17]. The current article is particularly focused on the utilization of different materials as liner, metallurgical advancements and geometry of the liner.

\section{MATERIALS FOR THE LINER OF SHAPED CHARGE}

At first, the material employed for liner fabrication was copper $(\mathrm{Cu})$. Its selection was based on its better elongation and moderate density [18]. It was found that steel liners with thickness up to $1 \mathrm{~mm}$ perform better against armor plates than the grey-iron casting having thickness up to $1.5 \mathrm{~mm}$ [19]. The microstructures of $\mathrm{Cu}$ and tantalum $(\mathrm{Ta})$ liners were compared in [20]. The density of the liner plays an important role in penetration because the square root of the liner's density is directly proportional to its penetration [21]:

$$
P \propto \sqrt{\rho_{\text {liner }}}
$$

The exact form of the equation is:

$$
P=L * \sqrt{\lambda * \rho_{\text {liner }} / \rho_{\text {target }}}
$$

where $P, L, \lambda$, and $\rho$ denote penetration, jet length, a constant having value between 1 and 2 and density respectively [22]. It was found that brass and lead's $(\mathrm{Pb})$ performance is not better than $\mathrm{Cu}$ 's, and $\mathrm{Cu}$ with smaller gain performs better than with larger grain.

An alloy of $\mathrm{Cu}$ and tungsten (W) was used for liner in [23] and the experiments were observed using flash x-ray (FXR). Improved penetration for the subject alloy was observed due to the increased density and break-up time. The effects of jet rotation and SO on penetration were also studied. Because of its higher density, molybdenum (Mo) was tested as a liner in [24-25]. At high strain rate the jet penetration depends upon the square root of the jet density and its length as shown in (2), therefore using high density materials like Mo and $\mathrm{W}$ gives greater penetration in comparison to low density liners. Tungsten made liners were simulated and studied analytically in [26]. Shaped charge with reduced slug was patented by authors in [27]. The slug was reduced by introducing a double layer liner. The layer contacting the explosive disintegrates reducing the mass of the slug and the second layer produces the jet. Liner made of Al was used in [28] for penetration in concrete. The development of a Al jet and its penetration was modeled with the hydrodynamic tool CALE. Copper liners preheated to $400-600^{\circ} \mathrm{C}$ were investigated in [29]. It was found that heating increased penetration power. Liner of Mo was used in [30]. The material was analyzed with the analytical tool JETFORM, hydro-code GRIM and experimentally. The liner was manufactured using six different techniques. The jets captured with FXR were compared with the results obtained from analytical and hydro-code and were found in close agreement. $\mathrm{Cu}$ liners were used in [31-32]. Jet formation, elongation and its particulation for aluminium (Al), nickel (Ni), $\mathrm{Cu}, \mathrm{Mo}, \mathrm{Ta}$, uranium and $\mathrm{W}$ as liner materials were studied in [31] and the conclusion was that $\mathrm{Cu}, \mathrm{Mo}$ and $\mathrm{W}$ have better properties for shaped charge liner. Silver, zirconium, titanium and depleted uranium (DU) were tested as liners in [33]. All produced a ductile jet having longer breakup time than $\mathrm{Cu}$. It was concluded that these four materials give better performance at longer $\mathrm{SO}$ when compared to $\mathrm{Cu}$.

The use of DU for liner was abondoned on the basis of its toxicity and radiation hazards. A study of liner made-up of a W-Cu-Ni alloy was carried out in [34]. Cu with $20 \% \mathrm{~Pb}$ was investigated with 2-D hydro-code in [35] to create a bigger hole in well casing and a small hole in the firing gun at the same time. Because of high densities and high or moderate sound velocities Mo, Ta, W, and their alloys were studied in [36] for liners of shaped charges and explosively formed penetrators. The jet breakup was studied experimentally and numerically in [37]. The formula for the jet break up time published in 1979 was further investigated by authors in [38] using a $\mathrm{Cu}$ liner. The effects in the variation of constants used in the formula by changing liner material, thickness, metallurgical state, and type of explosive were also included. $\mathrm{Al}, \mathrm{Cu}$, and $\mathrm{W}$ were investigated analytically and experimentally against hard rocks and concrete in [39]. The effect of current flow in $\mathrm{Cu}$ jet was investigated in [40]. It was found that when injecting high current in the liner, the jet tip is less affected, whereas distortion of the jet is observed where the jet particles are not aligned along the jet axis by FXR. The effect of magnetic field on a $\mathrm{Cu}$ liner showed that increasing the field decreases the penetration [41]. $\mathrm{Cu}$ liner was further analyzed in [42] using Autodyn. Changes in the shape of the jet by the detachment of explosive from the casing, air bubbles inside the explosive, eccentric initiation and dimensional inaccuracies in the liner were analyzed at different SO distances. The Tandem warhead consists of two warheads: the precursor fitted at the front and the main warhead fitted after the precursor at some distance. It is mostly used against armored vehicles protected by explosive reactive armor (ERA). The precursor of the tandem detonates on the ERA mounted on the armored vehicle and the main warhead then attacks the bare armored vehicle. $\mathrm{Cu}, \mathrm{Al}$ and steel liners were tested experimentally in [43] considering their incorporation in tandem warheads against concrete. It was found that a smaller diameter deep hole is produced by $\mathrm{Cu}$ liner when compared to the Al liner. The hole diameter and depth produced by steel liner is intermediate among the ones caused by $\mathrm{Cu}$ and $\mathrm{Al}$. Comparative numerical and experimental study of $\mathrm{Cu}$ and $\mathrm{Cu}-\mathrm{W}$ liners with the same charge to mass of the liner was carried out in [44]. The tip velocity of the jets obtained from both liners is the same in the air but when the target was submerged in water the jet tip velocity of $\mathrm{Cu}-\mathrm{W}$ liner decreased slowly in comparison with $\mathrm{Cu}$ liner. Zirconium was utilized as a liner material in [45]. 
Bimetallic liners were studied by authors in [46] whereas bimetallic and reactive liners were studied experimentally in [47]. It was concluded that a single metal liner is better than a bimetallic liner. Multi-material liners were studied numerically in [48] and it was suggested that they can be utilized for military purposes or in well perforation. The effect of a magnetic field on the penetration of a magnetized liner was analyzed in [49]. Jet penetration was reduced in the presence of an axial magnetic field in the liner just before the shot, and a transverse field in the conducting target. The decreased penetration was caused by the amplification of the magnetic field in the jet formation region. A study of the jet formation in the initial stages from Al liners was conducted in [50]. The simulated results were validated by experiments. OFHC (oxygen free high conductivity) copper was used in both simulations and experiments against steel submerged in the water behind the air gap in [51]. Polytetrafluoroethylene (PTFE) with added $\mathrm{Cu}$ powder was used in [52] as a shaped charge jet. $\mathrm{Cu}$ powder was added to improve penetration and mechanical properties of normal PTFE. Improved mechanical properties were verified by static compression and split Hopkinson pressure bar test. The interaction of $\mathrm{Cu}-\mathrm{W}$ jet with the target material was investigated in [53]. For this reason, three target materials $\mathrm{Cu}$, carbon steel, and Ti-6Al-4V alloy were selected for penetration. The penetration depth ratio was found to be 10:28:21 respectively which indicated that the same jet behaves differently when the target material is changed. OFHC Cu was utilized by authors in [54] in order to study the effects of drift velocity and SO distance between jet particles on penetration. Addition of zinc $(\mathrm{Zn})$ and $\mathrm{Ni}$ in the $\mathrm{Cu}-\mathrm{W}$ alloy for was studied in [55]. It was found that $\mathrm{W}-\mathrm{Cu}-$ $\mathrm{Zn}$ and $\mathrm{W}-\mathrm{Cu}-\mathrm{Ni}$ alloys have decreased target penetration because of the transverse dissipation of jet energy. Addition of $\mathrm{Zn}$ in the alloy decreased the melting point of the matrix, making it easier to melt and squeeze out. This reduced the lubrication effect of the matrix and the interaction between the $\mathrm{W}$ particles and the targets was facilitated. The addition of $\mathrm{Ni}$ in the alloy increases the melting point of the matrix phase making it harder to melt. As a result, the lubrication effect decreased. The interaction between jets and targets and the transverse dissipation of the jet energy are the consequences of reduced lubrication, leading to decreased penetration. The damage mechanism in thick concrete was investigated numerically and experimentally in [56] with $\mathrm{Al}$ and $\mathrm{Cu}$ liners. Experiments showed that the conical Al liner had higher destructive power than $\mathrm{Cu}$ liners in concrete. $\mathrm{Al}$ and $\mathrm{Cu}$ were also investigated numerically in [57] using LS-DYNA. Less penetration but bigger hole diameter in concrete-like targets for Al liner were observed. Low-density materials, namely float glass, lucite, and perspex were simulated as precursor shaped charge liner for tandem warhead against ERA in [58]. Simulation by Autodyn-2D showed that the jets from lowdensity liners were better than $\mathrm{Cu}$ liner's in terms of jet tip velocity, ductility, and jet tip diameter. These low-density liners did not create any hindrance to the main jet, so they can be utilized as precursor liner materials against ERA. Steel, Al, and $\mathrm{Cu}$ were utilized against spaced and layered concrete in [59]. Length and diameter of shaped charges were $60 \mathrm{~mm}$ and the target was $120 \mathrm{~mm}$ away. It was found by experiments and simulations that regarding steel and $\mathrm{Cu}$ liners having cone angle smaller than $120^{\circ}$, the spaced target provided better protection than the layered target, but this was not true for $\mathrm{Al}$ liner. Considering cost effectiveness, $\mathrm{Cu}$ and $\mathrm{Al}$ are the best choices for RHA and concrete-like targets respecitively. For greater penetration, high density materials like Mo, W and DU are used but they are toxic and, above all, DU is radioactive. Against composite and spaced armor, reactive metal and reactive metal powder liners perform better than the earlier mentioned ones. Recently, research is focused on the liners made of reactive material which produces enhanced damage to the target [60].

\section{Metallurgical ADVAnCEMEnTs}

Metallic liners are mostly formed by machining, diepressing, or rolling. The liner produced by such techniques has two distinct parts, the jet and the slug. The slug is heavier and slower than the jet. The low-velocity slug pulls the jet from behind, decreases its performance and in some cases, it fills the hole created by the jet. This is undesirable in perforation of well casing. This drove researchers to powder metallurgy, where the liners are manufactured from metal powder by sintering. It is the process of compacting granules to form a solid material by heat or pressure without melting [61]. Early powder metallurgy was intended for high strength materials [62]. Initial experiments on liners made of a mixture of $\mathrm{W}$ or titanium powder with carbon were conducted in [63]. Liners fabricated with metal powder were studied in [64] using FXR. The hole diameter and penetrations in rolled homogeneous armor (RHA) were investigated at different stand-off distances. Various theoretical aspects which come across when interpreting the penetration of jet from the un-sintered powdered metal liner were discussed in [65]. The penetration model was improved by incorporating the jet's porous compressible nature. Experimental and numerical data on the powder liners made of $\mathrm{Cu}$ and $\mathrm{Cu}-\mathrm{W}$ are available in [66]. It was found that powder metallurgy technology has the potential to manufacture liners of small calibres up to several dozen millimetres and it enables designing and manufacturing liners in various shapes and chemical compositions, which is beyond the scopes of traditional manufacturing technology [66, 67]. Electroformed $\mathrm{Cu}$ liners were analyzed in [68] with backscattered Kikuchi patterns and optical microscopy. To get different grain sizes, the liners were annealed at 410,530 and $650^{\circ} \mathrm{C}$. The grain growth was firstly uniform and normal, but different and abnormal at ascending temperatures. The performance of $\mathrm{W}-\mathrm{Cu}$ powder liner is given in [69]. The penetration depth of non-sintered and sintered powder liners and of the spinning $\mathrm{Cu}$ plate liner were tested at SOs, showing that sintered powder liner performed better. Scanning electron microscope was used to study the morphology of the liners. Powder liner of Ni-Al was investigated in [70]. FXR was used to photograph the jet whereas $\mathrm{x}$-ray diffraction and optical and electron microscopy were utilized to investigate the reactive behavior of a liner. The effect of porosity on powder liners was investigated in [71]. Three types of liner made up of $\mathrm{Cu}, \mathrm{Al}$ and $\mathrm{Cu}-\mathrm{W}-\mathrm{Pb}$ of different cone angles and SOs were tested. It was found that penetration increases linearly in metal targets whereas the diameter of the entrance hole decreases linearly with decreasing $\mathrm{Al}$ content in the liner material. 
A detailed study of the sintered and non-sintered $\mathrm{Cu}$ liners with particle size below $20 \mu \mathrm{m}$ is given in [72]. Examination showed that the sintered powder liner of $\mathrm{Cu}$ is having higher purity, density, lower wall thickness, and better penetration compared to the non-sintered one. To get reactive liner, Al powder was sprayed over $\mathrm{Cu}$ [73]. Reactivity was confirmed by the recovered jet. Phase transformation also took place as traces of $\gamma$-alumina $\alpha$-alumina were found. $\mathrm{Cu}$ liner was sprayed with Al-Ni powder using a kinetic spray deposition method for enhanced reactive liner in [74]. Formation and penetration of jet composed of polymeric based reactive liner were studied numerically and observed by FXR in [75]. The liners were made by cold isostatic pressing at a pressure of $250 \mathrm{MPa}$. The numerical results were in good agreement with the experiments. A straight and continuous jet was formed from the reactive liner. Jet formation and particulation time for polymeric reactive liners is less than $\mathrm{Cu}$ liners due to lack of ductility. The hole produced by reactive liners had a bigger diameter and less depth compared to the one produced by $\mathrm{Cu}$. Penetration of a jet having variable density distribution was studied in [76]. A jet having variable density was produced from an un-sintered $\mathrm{Cu}-\mathrm{W}$ powder liner. A new analytical model was presented to describe this variable density jet phenomenon by incorporating modifications in the earlier established virtual origin model. An analytical model was validated by numerical and experimental results. The behavior of reactive liners and its demolition power was investigated in [77]. Experiments, numerical simulation, and theoretical analysis were carried out for this purpose. Liners manufactured by pressing and sintering of Al-PTFE in 26.5/73.5 weight per cent gave much better collateral damage to the target due to the release of chemical energy contained in reactive materials. The effect of density variation on the penetration was studied in [78]. To achieve different densities of the same material, liners were manufactured by cold isostatic and uniaxial pressing. Liners produced by the former technique have no density variation whereas those produced by the later have it along the liner height. Autodyn was utilized to study the effects of metal powder liner density. It was numerically found and experimentally confirmed that liners produced by uniaxial pressing are more efficient than isostatic pressed against RHA targets. New manufacturing techniques and new alloys were employed with the development of metallurgy. The new techniques are robust and reproducable in comparison to previous techniques like machining, rolling etc. and the new alloys perfrom better. The grain size was controlled for better performance. Currently, graphene powder is pressed to get shaped charge liners [79]. Isostatic and die pressed liners were compared and it was found that higher density is achieved by the former while the latter is more suitable for liner mass production. Sintered powder metal liners need to be further investigated as there is room for improvement.

\section{LINER GEOMETRIES}

The shape or geometry of a liner is an important factor regarding penetration [80]. The shape can be optimized according to the nature of the target, stand-off distance and required hole diameter. Shape manipulation started as early as the history of the lined cavity. The liner was introduced by Munroe and Neumann but it could not be concluded who discovered it first. WASAG (Westfalische Anhaltische Sprengstoff Actien Gesellschaft) patents in 1911 are about the lined cavity [19]. British Navy studied the liner for shaped charges for torpedoes in 1913. Scaled conical shaped charges with an apex angle of $42^{0}$ were studied by in 1960 [81]. Work on conical liners was carried out in 1963 [82] and a new analytical method of computing penetration variables for shaped-charge jets was found. In the same year, open apex conical liners with varied cone angles were tested to get hypervelocity pellet [83]. The ways to isolate the tip of a shaped charge jet from the rest of the jet and slug were discussed. In [84], conical liners of $60^{\circ}$ and $42^{\circ}$ were utilized to find their penetration in granite.

Magnetic field lines could be traced out by barium (Ba) ions because the sunlight is resonantly scattered by ions into several visible wavelengths and the ions move in a spiral path about magnetic field lines when travelling parallel to the field lines. To study this effect, hollow conical liners of Ba were detonated at an altitude of $500 \mathrm{~km}$ [85]. The study in [1] was conducted on $42^{\circ}$ conically liners to find which portion of the cone contributes to the tip of the jet. Experiments were performed on cones with apex filled to various heights to obtain efficient jet for penetration. The study on conical liners was pushed further by more recent researches. In [86], authors observed that the ductility of metals like $\mathrm{Al}$ and $\mathrm{Cu}$ increases by an order of magnitude when the strain rate is increased. The same was supported by the finding that the jet elongation at breakup is proportional to the jet velocity gradient times the breakup-time. This gave a correct size prediction of the average fragment dimension and a formula for the breakup time of jet for conical liners was deduced. A unified approach for the penetration of conical shaped charge is given in [87]. FXR was used to find the shape of the jet at specified intervals and the results were compared with the analytical predictions. Small conical shaped charges were utilized to initiate explosives in [88]. An analytical model for the calculation of the dynamic penetration of inclined shaped charges at some arbitrary standoff and for various obliquities of the target plate was given in [89]. The obtained analytical model could be easily applied to get penetration estimations by changing parameters for the shaped charge and target. Hemispherical shaped charges with tapered liners were introduced in [90]. Numerical simulations of the hemispherical and conical liners were conducted by authors in [91] using HELP and EPIC hydro-codes. The results predicted by the hydro-codes were confirmed by the experiments. Authors in [92] showed that the maximum depth of penetration for a jet can be calculated theoretically using the tip velocity of the jet, the distance of the target plate from the virtual origin of the jet, particulation time, the efficient residual velocity and the square root of the ratio of target to jet density. To prove the above-given relations, experiments were conducted with $150 \mathrm{~mm}$ base diameter shaped charges at 6,12 , and 24 calibres stand-off against RHA.

Conical, hemispherical and EFP liners were utilized in [11] against concrete with various materials and varying SO. Twodimensional simulations were carried in [93] to study the penetration of conical shaped charges and long rods. The shape was further innovated to star-shaped and carried out its threedimensional simulations with TREK-UP [94]. It was shown 
that the star shape can be optimized to get better efficiency. In [95], Al conical and trumpet liners with different thicknesses were investigated experimentally. The liners were tested against steel and sand targets at about 15 and $3 \mathrm{CD}$ (charge diameter) stand-off. FXR was utilized to find the jet characteristic. Hemispherical liners of degressive thickness were investigated numerically in [96]. Simulations were compared with the jets from conical liners having $10 \mathrm{CD}$ penetrations. It was found that the jets produced by hemispherical liners of degressive thickness have comparable head velocity and penetration power to the jets obtained from conical liners. The effects of conical, hemispherical and spherical-segment shaped liners over water-submerged steel plates were studied numerically using smooth particle hydrodynamics model in [80]. It was found that in submerged target the shock waves which reached the target earlier than the jet produced damage. EFP has better motion dynamics due to its spherical shape so it produced a high-pressure shock wave having higher damaging effects. Shaped charges are meant for deep penetration in the target but they produce a smaller diameter hole. Conical $\mathrm{Cu}$ liner was utilized in [97] as a precursor for tandem warhead against concrete targets. To get a 1:1 ratio of hole diameter to depth, a $\mathrm{W}$ type of shaped charge was introduced in [98]. W type liners were tested numerically and experimentally observed by high-speed photography.

Reproducibility is highly required in the production of any manufactured goods. In [99], an optimized and reproducible linear shaped charge was presented. Precision linear-shaped charges were developed in [100]. Linear shaped charges were designed in [101] using the LESCA code and in [102] using Autodyn. It was observed that linear-shaped charges behave like conical shaped charges in the process of jet penetration. Analytical steady-state equation of motion for the jet of linearshaped charges was given in [103] incorporating changes to the Birkhoff theory. The equation was verified by Autodyn simulations. Smooth particle hydrodynamic model was applied to study the process of linear-shaped charge formation and penetration in the steel target in [104]. Simulation results were in agreement with the experimental ones. Linear shaped charges were investigated using LS-DYNA in [105] and the simulation results were compared with the experimental ones. Liner thickness and SO distance were studied in [106] using ABAQUS and the results were validated by experiments. It was shown that jet penetration increased by choosing an optimum SO distance and by decreasing liner thickness. The availability of simulation software made possible predicting minor changes in the geometry of the liner, something that is almost impossible to do otherwise. Software can simulate minor changes like angle variation upto half degree and thickness upto $0.1 \mathrm{~mm}$ depending upon grid fineness. Simulations save a lot of money and time and make the process robust. Geometry plays a pivoting role in penetration enhancement and must be catered seriously.

\section{CONCLUSION}

Optimization of shaped charge is a great challenge as it involves multiple variables to be investigated. This paper is intended to update and provide guidelines for the readers in designing a shaped charge liner against numerous targets. The three variables, liner material, geometry, and liner metallurgy which play important role in the modeling of shaped charges have been discussed with references from the initial experimental and analytical studies whereas numerical simulations have also been reviewed and discussed. A design optimized for one type of target can give very less or even no penetration for another. Reactive metal liners were found well suited for concrete and concrete-like targets. With the development of powder metallurgy in the field of shaped charges, powder metal, and reactive powder metal liners were introduced and performed better than the earlier versions of metal liners. $\mathrm{Cu}$ liners created a deeper hole in RHA, compared to $\mathrm{Al}$ and steel liners. The current research status is given at the end of each section. It is not possible to use a universal design of a shaped charge for various targets. Ignoring the cost of production, sintered powder liners give better efficiency if tuned properly for all type of targets.

\section{REFERENCES}

[1] J. Carleone, R. Jameson, P. C. Chou, "The tip origin of a shaped charge jet", Propellants, Explosives, Pyrotechnics, Vol. 2, No. 6, pp. 126-130, 1977

[2] M. A. Lavrent'ev, "Cumulative charge and its operating principles", Uspekhi Matematicheskikh Nauk, Vol. 12, No. 4, pp. 41-56, 1957

[3] H. Shekhar, "Theoretical modelling of shaped charges in the last two decades (1990-2010): A review", Central European Journal of Energetic Materials, Vol. 9, No. 2, pp. 155-185, 2012

[4] J. Hetherington, P. Smith, Blast and ballistic loading of structures, CRC Press, 2014

[5] D. C. Pack, W. M. Evans, "Penetration by high-velocity (Munroe') jets: I", Physical Society, Section B, Vol. 64, No. 4, pp. 298, 1951

[6] H. Shekhar, "Explosive characteristics and shaped charge applications of nitromethane (NM): A review", Central European Journal of Energetic Materials, Vol. 9, No. 1, pp. 87-97, 2012

[7] W. Walters, "An overview of the shaped charge concept", 11th Annual ARL/USMA Technical Symposium, 2003

[8] P. C. Chou, W. Flis, "Recent developments in shaped charge technology", Propellants, Explosives, Pyrotechnics, Vol. 11, No. 4, pp. 99-114, 1986

[9] S. S. Samudre, U. R. Nair, G. M. Gore, R. K. Sinha, A. K. Sikder, S. N. Asthana, "Studies on an improved plastic bonded explosive (PBX) for shaped charges", Propellants, Explosives, Pyrotechnics, Vol. 34, No. 2, pp. 145-150, 2009

[10] V. P. Alekseevskii, "Penetration of a rod into a target at high velocity", Combustion, Explosion and Shock Waves, Vol. 2, No. 2, pp. 63-66, 1966

[11] M. J. Murphy, R. M. Kuklo, "Fundamentals of shaped charge penetration in concrete", 18th International Symposium On Ballistics, San Antonio, Texas, November 15-19, 1999

[12] K. Naeem, A. Hussain, "Development of a matlab code for plane wave lens and its validation by autodyn-2D", Engineering, Technology \& Applied Science Research, Vol. 8, No. 6, pp. 3614-3618, 2018

[13] W. Walters, A brief history of shaped charges, Army Research Laboratory, 2008

[14] G. Bloem. Shell for detonating caps, U.S. Patent 342423, 1886

[15] G. Birkhoff, D. P. MacDougall, E. M. Pugh, G. Taylor, "Explosives with lined cavities", Journal of Applied Physics, Vol. 19, No. 6, pp. 563-582, 1948

[16] K. Naeem, A. Hussain, "Numerical and experimental study of wave shaper effects on detonation wave front", Defence Technology, Vol. 14, No. 1, pp. 45-50, 2018

[17] M. Ahmed, A. Q. Malik, "A review of works on shaped charges", Engineering, Technology \& Applied Science Research, Vol. 7, No. 5, pp. 2098-2103, 2017 
[18] W. B. Li, W. B. Li, X. M. Wang, H. Zhou, "Effect of the liner material on the shape of dual mode penetrators", Combustion, Explosion and Shock Waves, Vol. 51, No. 3, pp. 387-394, 2015

[19] W. P. Walters, The shaped charge concept, Part 2, the history of shaped charges, Technical Report BRL-TR3158, USA Army Ballistic Research Laboratory, Aberdeen Proving Ground, 1990

[20] A. C. Gurevitch, L. E. Murr, H. K. Shih, C. S. Niou, A. H. Advani, D. Manuel, L. Zernow, "Characterization and comparison of microstructures in the shaped-charge regime: Copper and tantalum", Materials Characterization, Vol. 30, No. 3, pp. 201-216, 1993

[21] M. Held, Hydrodynamic theory of shaped charge jet penetration, Messerschmitt-Boolkow-Blohm, 1991

[22] A. Doig, "Some metallurgical aspects of shaped charge liners", Journal of Battlefield Technology, Vol. 1, No. 1, pp. 1-3, 1998

[23] W. T. Fu, Z. H. Rong, "Copper-tungsten shaped charge liner and its jet", Propellants, Explosives, Pyrotechnics, Vol. 21, No. 4, pp. 193-195, 1996

[24] A. Lichtenberger, N. Verstraete, D. Salignon, M. T. Daumas, J. Collard, "Shaped charges with molybdenum liner", 16th International Ballistics Symposium, San Francisco, USA, September 23-28, 1996

[25] E. L. Baker, A. Daniels, G. P. Voorhis, T. Vuong, J. Pearson, "Development of molybdenum shaped charge liners", 127th Annual Meeting and Exhibition of the Minerals, Metals \& Materials Society, February 15-19, San Antonio, USA, 1998

[26] K. G. Cowan, K. J. A. Mawella, D. J. Standing, B. Bourne, J. S. Jones, A. C. Kitney, "Analytical code and hydrocode modelling and experimental characterisation of shaped charges containing conical tungsten liners", 18th International Symposium on Ballistics, San Antonio, USA, November 15-19, 1999

[27] B. M. Grove, J. F. Lands, R. A. Parrott, Shaped charges having reduced slug creation, US Patent 6021714,2000

[28] M. J. Murphy, D. W. Baum, D. B. Clark, E. M. McGuire, S. C. Simonson, "Numerical simulation of damage and fracture in concrete from shaped charge jets", 6th International Conference on Mechanical and Physical Behaviour of Materials Under Dynamic Loading, Krakow, Poland, September 25-29, 2000

[29] A. V. Babkin, P. A. Bondarenko, S. V. Fedorov, S. V. Ladov, V. I. Kolpakov, S. G. Andreev, "Limits of increasing the penetration of shaped-charge jets by pulsed thermal action on shaped-charge liners", Combustion, Explosion and Shock Waves, Vol. 37, No. 6, pp. 727-733, 2001

[30] K. G. Cowan, B. Bourne, "Analytical code and hydrocode modelling and experimental characterisation of shaped charges containing conical molybdenum liners", 19th International Ballistic Symposium, Interlaken, Switzerland, May 7-11, 2001

[31] M. Held, "Liners for shaped charges", Journal of Battlefield Technology, Vol. 4, No. 3, pp. 1-7, 2001

[32] W. H. Tian, A. L. Fan, H. Y. Gao, J. Luo, Z. Wang, "Comparison of microstructures in electroformed copper liners of shaped charges before and after plastic deformation at different strain rates", Materials Science and Engineering: A, Vol. 350, No. 1-2, pp. 160-167, 2003

[33] B. Bourne, K. G. Cowan, J. P. Curtis, "Shaped charge warheads containing low melt energy metal liners", 19th International Ballistic Symposium, Interlaken, Switzerland, May 7-11, 2001

[34] W. F. L. T. G. Ruijun, W. Yuling, "A study on tungsten-copper-nickel alloy as shaped charge liner", Acta Armamentarii, Vol. 1, pp. 28, 2001

[35] W. H. Lee, "Oil well perforator design using 2D Eulerian code", International Journal of Impact Engineering, Vol. 27, No. 5, pp. 535559,2002

[36] Z. W. Hu, Z. K. Li, T. J. Zhang, X. M. Zhang, "Advanced progress in materials for shaped charge and explosively formed penetrator liners", Rare Metal Materials and Engineering, Vol. 33, No. 10, pp. 1009-1012, 2004

[37] J. Petit, V. Jeanclaude, C. Fressengeas, "Breakup of copper shapedcharge jets: Experiment, numerical simulations, and analytical modeling", Journal of Applied Physics, Vol. 98, No. 12, Article ID 123521,2005
[38] E. Hirsch, "Scaling of the shaped charge jet break-up time", Propellants, Explosives, Pyrotechnics, Vol. 31, No. 3, pp. 230-233, 2006

[39] M. Huerta, M. G. Vigil, "Design, analyses, and field test of a $0.7 \mathrm{~m}$ conical shaped charge", International Journal of Impact Engineering, Vol. 32, No. 8, pp. 1201-1213, 2006

[40] M. Wickert, "Electric armor against shaped charges: Analysis of jet distortion with respect to jet dynamics and current flow", IEEE Transactions on Magnetics, Vol. 43, No. 1, pp. 426-429, 2007

[41] S. V. Fedorov, A. V. Babkin, S. V. Ladov, G. A. Shvetsov, A. D. Matrosov, "On the possibility of reducing the penetration capability of shaped-charge jets in a magnetic field", Journal of Applied Mechanics and Technical Physics, Vol. 48, No. 3, pp. 393-400, 2007

[42] O. Ayisit, "The influence of asymmetries in shaped charge performance", International Journal of Impact Engineering, Vol. 35, No. 12, pp. 1399-1404, 2008

[43] C. Wang, T. Ma, J. Ning, "Experimental investigation of penetration performance of shaped charge into concrete targets", Acta Mechanica Sinica, Vol. 24, No. 3, pp. 345-349, 2008

[44] X. Zhang, C. Wu, F. Huang, "Penetration of shaped charge jets with tungsten-copper and copper liners at the same explosive-to-liner mass ratio into water", Shock Waves, Vol. 20, No. 3, pp. 263-267, 2010

[45] T. Elshenawy, Q. M. Li, "Breakup time of zirconium shaped charge jet", Propellants, Explosives, Pyrotechnics, Vol. 38, No. 5, pp. 703-708, 2013

[46] P. Y. Chanteret, A. Lichtenberger, "Bimetallic liners and coherence of shaped charge jets", 15th International Symposium on Ballistics, Jerusalem, Israel, May 21-24, 1995

[47] J. S. Mason, Experimental testing of bimetallic and reactive shaped charge liners, MSc Thesis, University of Illinois at Urbana-Champaign, 2010

[48] J. P. Curtis, R. Cornish, "Formation model for shaped charged liners comprising multiple layers of different materials", 18th International Symposium on Ballistics, San Antonio, USA, November 15-19, 1999

[49] G. A. Shvetsov, A. D. Matrosov, S. V. Fedorov, A. V. Babkin, S. V. Ladov, "Effect of external magnetic fields on shaped-charge operation", International Journal of Impact Engineering, Vol. 38, No. 6, pp. 521526,2011

[50] E. Scheid, T. D. Burleigh, N. U. Deshpande, M. J. Murphy, "Shaped charge liner early collapse experiment execution and validation", Propellants, Explosives, Pyrotechnics, Vol. 39, No. 5, pp. 739-748, 2014

[51] M. Ahmed, A. Q. Malik, S. A. Rofi, Z. X. Huang, "Penetration evaluation of explosively formed projectiles through air and water using insensitive munition: Simulative and experimental studies", Engineering, Technology \& Applied Science Research, Vol. 6, No. 1, pp. 913-916, 2016

[52] B. H. Chang, J. P. Yin, Z. Q. Cui, T. X. Liu, "Improved dynamic mechanical properties of modified PTFE jet penetrating charge with shell", Strength of Materials, Vol. 48, No. 1, pp. 82-89, 2016

[53] W. Q. Guo, J. X. Liu, Y. Xiao, S. K. Li, Z. Y. Zhao, J. Cao, "Comparison of penetration performance and penetration mechanism of w-cu shaped charge liner against three kinds of target: Pure copper, carbon steel and Ti-6Al-4V alloy", International Journal of Refractory Metals \& Hard Materials, Vol. 60, pp. 147-153, 2016

[54] Q. Q. Xiao, Z. X. Huang, X. D. Zu, X. Jia, "Influence of drift velocity and distance between jet particles on the penetration depth of shaped charges", Propellants, Explosives, Pyrotechnics, Vol. 41, No. 1, pp. 7683,2015

[55] Z. Zhao, J. Liu, W. Guo, S. Li, G. Wang, "Effect of Zn and Ni added in $\mathrm{W}-\mathrm{Cu}$ alloy on penetration performance and penetration mechanism of shaped charge liner", International Journal of Refractory Metals and Hard Materials, Vol. 54, pp. 90-97, 2016

[56] N. D. Gerami, G. H. Liaghat, G. H. R. S. Moghadas, N. Khazraiyan, "Analysis of liner effect on shaped charge penetration into thick concrete targets", Journal of the Brazilian Society of Mechanical Sciences and Engineering, Vol. 39, No. 8, pp. 3189-3201, 2017

[57] F. Hu, H. Wu, Q. Fang, J. C. Liu, "Numerical simulations of shaped charge jet penetration into concrete-like targets", International Journal of Protective Structures, Vol. 8, No. 2, pp. 237-259, 2017 
[58] L. Ding, W. Tang, X. Ran, "Simulation study on jet formability and damage characteristics of a low-density material liner", Materials, Vol. 11, No. 1, pp. 72, 2018

[59] C. Wang, W. Xu, S. C. K. Yuen, "Penetration of shaped charge into layered and spaced concrete targets", International Journal of Impact Engineering, Vol. 112, pp. 193-206, 2018

[60] J. Xiao, X. Zhang, Z. Guo, H. Wang, "Cover picture: Enhanced damage effects of multi-layered concrete target produced by reactive materials liner", Propellants, Explosives, Pyrotechnics, Vol. 43, No. 9, pp. 851851,2018

[61] R. M. German, Sintering theory and practice, Wiley-Interscience, 1996

[62] J. R. Pickens, "Aluminium powder metallurgy technology for highstrength applications", Journal of Materials Science, Vol. 16, No. 6, pp. 1437-1457, 1981

[63] Y. A. Trishin, S. A. Kinelovskii, "Effect of porosity on shaped-charge flow", Combustion, Explosion and Shock Waves, Vol. 36, No. 2, pp. 272-281, 2000

[64] W. Walters, P. Peregino, R. Summers, D. Leidel, A study of jets from unsintered-powder metal lined nonprecision small-caliber shaped charges, USA Army Ballistics Research Laboratory, Aberdeen Proving Ground, 2001

[65] B. Grove, "Theoretical considerations on the penetration of powdered metal jets", International Journal of Impact Engineering, Vol. 33, No. 112, pp. 316-325, 2006

[66] B. Zygmunt, Z. Wilk, "The research of shaped charges with powder liners for geological borehole perforation", Archives of Mining Sciences, Vol. 52, No. 1, pp. 121-133, 2007

[67] B. Zygmunt, Z. Wilk, "Formation of jets by shaped charges with metal powder liners", Propellants, Explosives, Pyrotechnics, Vol. 33, No. 6, pp. $482-487,2008$

[68] A. Fan, S. K. Li, W. H. Tian, "Grain growth and texture evolution in electroformed copper liners of shaped charges", Materials Science and Engineering: A, Vol. 474, No. 1-2, pp. 208-213, 2008

[69] Y. Gao, X. Gu, T. Liu, "Sintering effect on the performance of tungstencopper powder liner", Journal of Wuhan University of TechnologyMaterials Science Edition, Vol. 27, No. 6, pp. 1133-1136, 2012

[70] P. Church, R. Claridge, P. Ottley, I. Lewtas, N. Harrison, P. Gould, C. Braithwaite, D. Williamson, "Investigation of a nickel-aluminum reactive shaped charge liner", Journal of Applied Mechanics, Vol. 80, No. 3, Article ID 031701, 2013

[71] Y. I. Voitenko, S. V. Goshovskii, A. G. Drachuk, V. P. Bugaets, "Mechanical effect of shaped charges with porous liners", Combustion, Explosion and Shock Waves, Vol. 49, No. 1, pp. 109-116, 2013

[72] N. Duan, Y. Gao, J. Wang, W. Du, F. Wang, "The properties of the sintered copper powder liner", Journal of Wuhan University of Technology-Materials Science Edition, Vol. 29, No. 2, pp. 269-272, 2014

[73] J. Won, G. Bae, K. Kang, C. Lee, S. J. Kim, K. A. Lee, S. Lee, "Bonding, reactivity, and mechanical properties of the kinetic-sprayed deposition of al for a thermally activated reactive $\mathrm{Cu}$ liner", Journal of Thermal Spray Technology, Vol. 23, No. 5, pp. 818-826, 2014

[74] G. Byun, J. Kim, C. Lee, S. J. Kim, S. Lee, "Kinetic spraying deposition of reactive-enhanced $\mathrm{Al}-\mathrm{Ni}$ composite for shaped charge liner applications", Journal of Thermal Spray Technology, Vol. 25, No. 3, pp. 483-493, 2016

[75] Y. Wang, Q. Yu, Y. Zheng, H. Wang, "Formation and penetration of jets by shaped charges with reactive material liners", Propellants, Explosives, Pyrotechnics, Vol. 41, No. 4, pp. 618-622, 2016

[76] T. Elshenawy, A. Elbeih, Q. M. Li, “A modified penetration model for copper-tungsten shaped charge jets with non-uniform density distribution", Central European Journal of Energetic Materials, Vol. 13, No. 4, pp. 927-943, 2016

[77] J. Xiao, X. Zhang, Y. Wang, F. Xu, H. Wang, "Demolition mechanism and behavior of shaped charge with reactive liner", Propellants, Explosives, Pyrotechnics, Vol. 41, No. 4, pp. 612-617, 2016
[78] T. Elshenawy, "Density effect of the compacted copper-tungsten shaped charge powder liners on its penetration performance", Journal of Powder Metallurgy \& Mining, Vol. 6, No. 2, pp. 1-6, 2017

[79] T. Majewski, A. Jackowski, "Use of graphene for shaped charge liner materials", Problemy Mechatroniki: Uzbrojenie, Lotnictwo, Inzynieria Bezpieczenstwa, Vol. 9, No. 3, pp. 15-28, 2018

[80] Z. Zhang, L. Wang, V. Silberschmidt, "Damage response of steel plate to underwater explosion: Effect of shaped charge liner", International Journal of Impact Engineering, Vol. 103, pp. 38-49, 2017

[81] R. DiPersio, J. Simon, T. H. Martin, A study of jets from scaled conical shaped charge liners, Ballistic Research Laboratories, 1960

[82] F. E. Allison, R. Vitali, A new method of computing penetration variables for shaped-charge jets, USA Army Ballistics Research Laboratory, Aberdeen Proving Ground, 1963

[83] A. Merendino, J. M. Regan, S. Kronman, A method of obtaining a massive hypervelocity pellet from a shaped charge jet, USA Army Ballistics Research Laboratory, Aberdeen Proving Ground, 1963

[84] R. R. Rollins, G. B. Clark, H. N. Kalia. "Penetration in granite by jets from shaped-charge liners of six materials", International Journal of Rock Mechanics and Mining Sciences \& Geomechanics Abstracts, Vol. 10, No. 3, pp. 183-200, 1973

[85] E. M. Wescott, E. P. Rieger, H. C. Stenbaek-Nielsen, T. N. Davis, H. M. Peek, P. J. Bottoms, " $\mathrm{L}=1.24$ conjugate magnetic field line tracing experiments with barium shaped charges", Journal of Geophysical Research, Vol. 79, No. 1, pp. 159-168, 1974

[86] E. Hirsch, "A formula for the shaped charge jet breakup time", Propellants, Explosives, Pyrotechnics, Vol. 4, No. 5, pp. 89-94, 1979

[87] M. J. Murphy, Shaped-charge penetration in concrete: a unified approach, $\mathrm{PhD}$ Thesis, University of California, 1983

[88] M. Vigil, Explosive initiation by very small conical shaped charge jets, Sandia National Labs, 1985

[89] M. Held, R. Fischer, "Penetration theory for inclined and moving shaped charges", Propellants, Explosives, Pyrotechnics, Vol. 11, No. 4, pp. 115122,1986

[90] C. Aseltine, W. Walters, A. Arbuckle, J. Lacetera, "Hemispherical shaped charges utilizing tapered liners", 4th International Symposium on Ballistics, Monterey, USA, September 17-19, 1978

[91] W. P. Walters, S. K. Golaski, Hemispherical and conical shaped-charge liner collapse and jet formation, Technical Report BRL-TR-2781, USA Army Ballistic Research Laboratory, Aberdeen Proving Ground, 1987

[92] M. Held, "Penetration cutoff velocities of shaped charge jets", Propellants, Explosives, Pyrotechnics, Vol. 13, No. 4, pp. 111-119, 1988

[93] Z. Rosenberg, E. D. Rafael, "Use of 2D simulations to study penetration mechanisms of long rods and shaped charge jets", Chemical Physics Reports, Vol. 18, No. 10, pp. 2047-2059, 2000

[94] V. I. Tarasov, Y. V. Yanilkin, Y. A. Vedernikov, "Three-dimensional simulation of shaped charges with a star-shaped liner", Combustion, Explosion and Shock Waves, Vol. 36, No. 6, pp. 840-844, 2000

[95] S. Saran, O. Ayisit, M. S. Yavuz, "Experimental investigations on aluminum shaped charge liners", Procedia Engineering, Vol. 58, pp. 479-486, 2013

[96] S. V. Fedorov, "Numerical simulation of the formation of shaped-charge jets from hemispherical liners of degressive thickness", Combustion, Explosion and Shock Waves, Vol. 52, No. 5, pp. 600-612, 2016

[97] N. D. Gerami, G. H. Liaghat, G. H. Rahimi, N. Khazraiyan, "The effect of concrete damage on the penetration depth by the tandem projectiles", Proceedings of the Institution of Mechanical Engineers, Part C: Journal of Mechanical Engineering Science, Vol. 232, No. 6, pp. 1020-1032, 2018

[98] C. Wang, F. Huang, J. Ning, "Jet formation and penetration mechanism of W typed shaped charge", Acta Mechanica Sinica, Vol. 25, No. 1, pp. 107-120, 2009

[99] M. G. Vigil, J. G. Harlan, Optimal design and fabrication of reproducible linear shaped charges, Technical Report, Sandia National Labs, 1986 
[100]M. G. Vigil, "Design and development of precision linear shaped charges", International Symposium on Detonation, Portland, USA, August 28-September 1, 1989

[101] M. Vigil, Design of linear shaped charges using the LESCA code, Technical Report SAND90-0243, Sandia National Laboratories, 1990

[102] M. Johnston, S. Lim, "Numerical observation of the jet flight patterns of linear shaped charges", Applied Sciences, Vol. 2, No. 4, pp. 629-640, 2012

[103] S. Lim, "Steady state analytical equation of motion of linear shaped charges jet based on the modification of Birkhoff theory", Applied Sciences, Vol. 2, No. 4, pp. 35-45, 2012

[104] D. Feng, M. B. Liu, H. Li, G. R. Liu, "Smoothed particle hydrodynamics modeling of linear shaped charge with jet formation and penetration effects", Computers \& Fluids, Vol. 86, pp. 77-85, 2013

[105]A. Wojewodka, T. Witkowski, "Methodology for simulation of the jet formation process in an elongated shaped charge", Combustion, Explosion and Shock Waves, Vol. 50, No. 3, pp. 362-367, 2014

[106] P. Dehestani, A. Fathi, H. M. Daniali, "Numerical study of the stand-off distance and liner thickness effect on the penetration depth efficiency of shaped charge process", Proceedings of the Institution of Mechanical Engineers, Part C: Journal of Mechanical Engineering Science, Vol 233, No. 3, pp. 977-986, 2018 